\title{
Reversal by aqueous extracts of Cistanche tubulosa from behavioral deficits in Alzheimer's disease-like rat model: relevance for amyloid deposition and central neurotransmitter function
}

\author{
Chi-Rei Wu ${ }^{1 *}$, Hang-Ching Lin ${ }^{2,3+}$ and Muh-Hwan Su' ${ }^{2,3+}$
}

\begin{abstract}
Background: Cistanche tubulosa (Schenk) R. Wight (CT) is commonly used to treat forgetfulness by traditional Chinese physicians. This study presents the ameliorating effects of $\mathrm{CT}$ extract which was quantified with three phenylpropanoid glycosides in Alzheimer's disease (AD)-like rat model.

Methods: Amyloid $\beta$ peptide 1-42 (A 1 1-42) intracisternally infused to rats by osmotic pump (Alzet 2002) was used as an AD-like rat model. The major pathological makers were measured including A 1 1-42 immunohistochemical stain, behavioral tests (inhibitory avoidance task and Morris water maze) and central neurotransmitter functions.

Results: A 1-42 caused the cognitive deficits, the increase in the amyloid deposition and acetylcholinesterase activities, and the decrease in the levels of brain's acetylcholine and dopamine. Daily administration of CT extract throughout $A \beta$ 1-42 infusion periods ameliorated the cognitive deficits, decreased amyloid deposition and reversed cholinergic and hippocampal dopaminergic dysfunction caused by Aß 1-42. Donepezil also ameliorated the cognitive dysfunction, but only blocked the amyloid deposition and cholinergic dysfunction caused by A 1 1-42.

Conclusions: We suggest that $\mathrm{CT}$ extract, containing enough echinacoside and acteoside, ameliorated the cognitive dysfunction caused by Aß 1-42 via blocking amyloid deposition, reversing cholinergic and hippocampal dopaminergic neuronal function.
\end{abstract}

Keywords: Cistanche tubulosa, Amyloid $\beta$ peptide 1-42, Morris water maze, Acetylcholine, Dopamine

\section{Background}

Alzheimer's disease (AD), a progressive neurodegenerative disorder, is characterized by cognitive deficits and three neuropathological hallmarks: neuronal loss, senile plaques and neurofibrillary tangles [1]. The major pathogenesis of $\mathrm{AD}$ includes the cholinergic hypothesis and the amyloid cascade hypothesis [2]. The core feature of amyloid cascade hypothesis is the formation of the byproduct amyloid $\beta$ peptide $(A \beta)$ from amyloid precursor protein via amyloidogenic pathway $[1,2]$. When $A \beta$ is deposited in the brain, it is associated with cerebral neuronal loss, particularly the

\footnotetext{
* Correspondence: crw@mail.cmu.edu.tw

${ }^{\dagger}$ Equal contributors

'Department of Chinese Pharmaceutical Sciences and Chinese Medicine Resources, College of Pharmacy, China Medical University, No. 91, Hsieh Shih Road, Taichung 40402, Taiwan

Full list of author information is available at the end of the article
}

degeneration of cholinergic neuronal circuits in the basal forebrain (the cholinergic hypothesis) [2,3]. A series of studies suggested that the intracisternal infusion of $A \beta$ 1-42 into rats was primarily deposited in the frontal cortex and the hippocampus, causing memory deficits in behavioral tasks including inhibitory avoidance task and Morris water maze [3,4]. Thus, the intracisternal infusion of $A \beta$ 1-42 into the lateral ventricle has been used to induce AD-like pathological and behavioral changes in animal model [3].

Cistanche tubulosa (Schenk) R. Wight (abbreviated as $\mathrm{CT}$ ) is commonly used by traditional Chinese physicians to treat forgetfulness, impotence and senile constipation [5]. Recent studies have shown that pretreatment with total phenylethanoid glycosides of CT could improve the impairment of inhibitory avoidance response and neuronal 
apoptosis caused by quinolinic acid, $A \beta$ 25-35, or common carotid artery ligation in mice [6-8] via its antioxidant activity and increasing the activities of intracellular antioxidant enzymes such superoxide dismutase and glutathione peroxidase [9]. Total phenylethanoid glycosides mainly include 2'-acetylacteoside, acteoside, cistanosides, echinacoside and isoacteoside [10]. Echinacoside and acteoside can prevent the memory impairment caused by scopolamine in mice $[11,12]$. Therefore, we hypothesized that $\mathrm{CT}$ may have beneficial effects in $\mathrm{AD}$ patients. To test this hypothesis, we used CT extract which the contents of phenylpropanoid glycosides were quantified to investigate the effects against amyloid-induced histopathological and behavioral changes in an AD-like rat model. According to a meta-analysis of Myhrer on four behavioral tasks [13], acetylcholinergic and catecholaminergic activities have a high influence on learning and memory. The AD-like rat model causes the dysfunction of central neurotransmitters such as acetylcholine and catecholamines, which is closely related to memory deficits $[3,14]$. Hence, we further demonstrated the role of central neurotransmitter function in $\mathrm{CT}$ extract-induced reversal of memory impairment caused by $A \beta$ 1-42 infusion by measuring the levels of central neurotransmitters and the activities of related enzymes.

\section{Methods}

\section{Preparation of plant extract}

The dried materials of Cistanche tubulosa (Schenk) Wight (Citu970429) were identified by Development Center for Biotechnology (Taipei, Taiwan, R.O.C.) and deposited in Sinphar Tian-Li Pharmaceutical Co., Ltd. (Hangzhou, China). The aqueous extract of CT contains three phenylethanoid glycosides, echinacoside (25.4\%), acteoside $(3.8 \%)$, and isoacteoside $(4.1 \%)$, which were quantified by high performance liquid chromatography plus photodiodearray detector according to the method of Jiang et al [9]. CT extract was freshly prepared with sterile distilled water.

\section{Subjects}

Male Sprague-Dawley rats weighing 300-350 g, obtained from BioLASCO Taiwan Co. Ltd., were used in present study. They were randomly housed at a density of four rats per wire-mesh cage $(39 \times 26 \times 21 \mathrm{~cm})$ in a temperature$\left(23 \pm 1^{\circ} \mathrm{C}\right)$ and humidity- $(60 \%)$ regulated environment with free access to standard food in pellets and tap water and, on a $12 \mathrm{~h}-12 \mathrm{~h} \mathrm{light/dark}$ cycle (light phase: 08:00 to 20:00 h). The experimental protocol (Protocol No. 99127-B) was approved by the Institutional Animal Care and Use Committee (IACUC) of China Medical University and the care of animal was carried out according to the Guiding Principles for the Care and Use of Laboratory
Animals. After 1 week of acclimatization, rats were used for the below experiments.

\section{AD-like rat model}

The AD-like rat model was developed by infusing A $\beta$ 1-42 into the cerebral ventricle [4]. Briefly, rats were anesthetized with phenobarbital ( $45 \mathrm{mg} / \mathrm{kg}$, i.p.) and positioned in a David Kopf stereotaxic instrument. An infusion cannula was implanted into the left cerebral ventricle (AP -1.5, $\mathrm{ML}+0.9, \mathrm{~V}-3.6$ from bregma), and a continual infusion of $A \beta 1-42$ (300 pmol/day) was maintained for at least two weeks by attaching an infusion cannula to a miniosmotic pump (Alzet 2002; Alza, Palo Alto, CA, USA).

\section{Experimental schedule}

After the implantation of the cannula and the attachment of the mini-osmotic pump, $A \beta$ 1-42 infusion began, and this day was designated as day 0 . On the next day (day 1 ), the rats were orally given with sterile distilled water, CT extract $(100,200 \mathrm{mg} / \mathrm{kg})$ or donepezil $(0.75 \mathrm{mg} / \mathrm{kg})$ throughout A $\beta$ 1-42 infusion period. CT extract (100, $200 \mathrm{mg} / \mathrm{kg})$ or donepezil $(0.75 \mathrm{mg} / \mathrm{kg})$ was also still given to rats $1 \mathrm{~h}$ before the behavioral tests, including open field test and hole test (day 7 after $A \beta$ 1-42 infusion), inhibitory avoidance test (day 8-9 after $A \beta$ 1-42 infusion) and Morris water maze (day 10-14 after $A \beta$ 1-42 infusion). On day 15 after $A \beta \quad 1-42$ infusion, the rats were killed $1 \mathrm{~h}$ after the last administration of $\mathrm{CT}$ extract $(100,200 \mathrm{mg} / \mathrm{kg})$ or donepezil $(0.75 \mathrm{mg} / \mathrm{kg})$ for the measurement of acetylcholinesterase (AChE) and monoamine oxidase (MAO) activities in the brain and the levels of central neurotransmitters and their metabolites. The schedule for surgery, drug treatment, and behavioral tests is shown in Figure 1.

\section{Locomotor and exploratory activities}

Locomotor and exploratory activities were measured by an open-field task (Coulbourn Instruments L.L.C., PA, USA). Each animal was placed individually at the apparatus and observed for $10 \mathrm{~min}$ to record the movement time, length and velocity (locomotor activity), entries into the hole and time spent (exploratory activity) by TruScan software v 2.07 (Coulbourn Instruments L.L.C., PA, USA) [15].

\section{Inhibitory avoidance test}

The inhibitory avoidance apparatus for rats (Coulbourn Instruments L.L.C., PA, USA) was used. The room was dark during the experimental sessions that were conducted between 09:00 and 12:00. During the training trial (day 8), each rat was placed in the light compartment with its back to the guillotine door and the time (step-through latency) was measured until the rat entered the dark compartment. After the rat entered the dark compartment, 


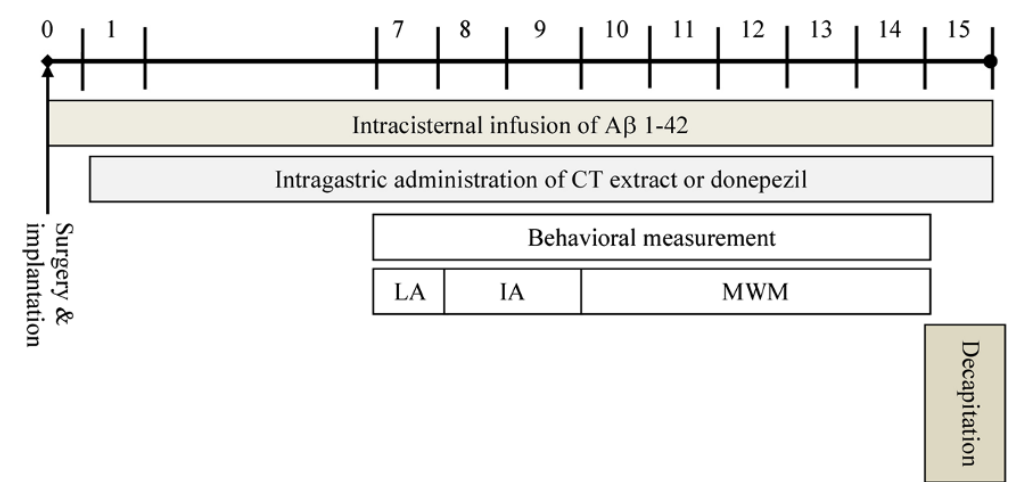

Figure 1 Experimental schedule. LA: Locomotor activity assay, IA: Inhibitory avoidance test, MWM: Morris water maze test.

the door was closed. An inescapable foot shock (0.8 mA for $2 \mathrm{~s}$ ) was delivered through the grid floor. The rat was removed from the dark compartment $5 \mathrm{~s}$ after the shock. Then, the rat was put back into its home cage until the retention trial. Twenty-four hours later, the retention trial (day 9) was conducted. The rat was again placed in the light compartment, the door was opened and the stepthrough latency was recorded as a measure of memory retention [15]. An upper cut-off time of $300 \mathrm{sec}$ was set.

\section{Morris water maze task}

For the assessment of spatial performance function, the rats were tested in a Morris water maze, which consisted of a black circular stainless pool (a diameter of $165 \mathrm{~cm}$ and a height of $60 \mathrm{~cm}$ ), filled with $23 \pm 1^{\circ} \mathrm{C}$ water to a depth of $35 \mathrm{~cm}$. The maze was divided geographically into four equal quadrants and included release points in each quadrant. The position of white rat in the black pool was recorded by a video camera and an automated video tracking system device equipped with EthoVision $\mathrm{XT}$ software (Noldus Information Technology, Leesburg, VA, USA). The swim path and escape latency to find the platform were recorded for each trial. Each rat was given two trials per day for four consecutive days (day 10 - 13 after $A \beta$ 1-42 infusion) to find the Plexiglass hidden platform (a diameter of $10 \mathrm{~cm}$ ) that was situated in the center of the northeast quadrant and submerged $1.0 \mathrm{~cm}$ below the surface of the water. A trial was initiated by placing the rat in the water facing the pool wall in one of the four quadrants. For each trial, the rat was allowed to swim for maximum of $120 \mathrm{sec}$ to find the platform. When successful, the rat was allowed a $30-\mathrm{sec}$ rest period on the platform. If unsuccessful within the aborted time period, the rat was given a score of $120 \mathrm{sec}$ and then physically placed on the platform and allowed the 30-sec rest period. In either case, the rat was immediately given the next trial after the rest period [15]. The day following four daily sessions (day 14), the probe test was performed as a measure of reference memory. The Plexiglass platform was removed from the pool, and each rat was released from the quadrant opposite to where the platform had been located. The parameters measured from probe test during $60 \mathrm{~s}$ were time and distance in each quadrant especial spent searching for the platform in the training quadrant, and swimming speed [15].

\section{$A \beta$ 1-42 immunohistochemical stain}

Rats were anesthetized with sodium pentobarbital $(45 \mathrm{mg} / \mathrm{kg}$ ) and perfused with saline through their left cardiac ventricle, followed by $4 \%$ paraformaldehyde in physiological saline. After postfixation, the whole brain was removed and prepared for paraffin slices. Three brain sections $(10 \mu \mathrm{m})$ of each rat were obtained on a microtome (Leica 2030 Biocut). The tissues were incubated overnight at $4{ }^{\circ} \mathrm{C}$ with a mouse anti-human amyloid $\beta$ protein $17-24$ monoclonal antibody (1:300 dilution, Dakopatts A/C; Glostrup, Denmark). Immunolabeled sections were developed with $0.05 \%$ diaminobenzidine using a Vectastain kit (Vector Laboratories, Burlingame, CA, USA). Brain sections were measured under $40 \mathrm{x}$ magnification, and at least 20 fields from each brain section were counted by an image analyzer (Leica, Q500MC, Nussloch, Germany).

\section{Measurement of cortical and hippocampal neurotransmitter levels}

For the measurement of acetylcholine levels, rats were sacrificed by microwave irradiation. For the measurement of catecholamine levels, rats were decapitated. Their brains were rapidly removed from the skull and immediately separated into the cortex and hippocampus on ice according to the protocol of Glowinski and Iversen [16]. Then, all brain tissues were homogenized with ice-cold $0.2 \mathrm{M}$ perchloric acid and centrifuged at $14,000 \mathrm{rpm}$ for $15 \mathrm{~min}$ at $4^{\circ} \mathrm{C}$. The supernatants were collected, put into $0.22 \mu \mathrm{M}$ Ultrafree $\mathrm{MC}$ centrifugal filter units (Millipore, USA) and again centrifuged for $5 \mathrm{~min}$ at $4^{\circ} \mathrm{C}$. The collected samples were stored at $-80^{\circ} \mathrm{C}$ for the measurement of the concentrations of central 
neurotransmitters and their metabolite by high performance liquid chromatography with electrochemical detection (EICOM HTEC-500, Japan).

\section{Determination of cortical and hippocampal AChE and MAO activity}

Each cortex and hippocampus were homogenized in 9 vol ice-cold phosphate buffered saline. Homogenates were centrifuged at $12,000 \mathrm{rpm}$ for $15 \mathrm{~min}$ at $4^{\circ} \mathrm{C}$, and the supernatants were stored at $-80^{\circ} \mathrm{C}$ until use. AChE activity was measured using Ellman method [17]. Brain homogenates were incubated with 5,5'-dithiobis(2-nitrobenzoic acid) at $25^{\circ} \mathrm{C}$ for $10 \mathrm{~min}$ and then acetylthiocholine was added for color development. The production of 5-thio-2-nitrobenzoic acid was measured at $412 \mathrm{~nm}$. AChE activity was expressed as $\mathrm{U}$ AChE per mg protein. MAO-A and MAO-B activities were determined by incubating the reaction mixture including rat brain homogenates, $5 \mathrm{U} / \mathrm{mL}$ horseradish peroxidase, $100 \mu \mathrm{M}$ amplex red, and the substrate $(5 \mathrm{mM}$ serotonin for MAO-A or $5 \mathrm{mM}$ benzylamine for MAO-B) at $25^{\circ} \mathrm{C}$ for $60 \mathrm{~min}$. The enzyme activity was expressed as the percentage of the activity relative to vehicle-infused rats [18]. The protein content was determined with a BioRad protein assay kit using bovine serum albumin as a standard.

\section{Statistical analysis}

The data of inhibitory avoidance test was analyzed using a Kruskal-Wallis non-parametric one-way analysis of variance, followed by Mann-Whitney's $U$-test. The data from spatial performance, probe test, the ratio of amyloid deposition, the activities of AChE and MAO, and the levels of central neurotransmitters and their metabolites were subjected to a one-way analysis of variance (ANOVA) followed by Scheff's test. The criterion for statistical significance was $P<0.05$ in all statistical evaluations.

\section{Results}

\section{Effects of CT or donepezil on locomotor and exploratory} activities

There was no difference in movement time, length or velocity between vehicle-infused and $A \beta$ 1-42-infused groups $(P>0.05)$. CT extract $(100,200 \mathrm{mg} / \mathrm{kg})$ or donepezil $(0.75 \mathrm{mg} / \mathrm{kg})$ did not alter the movement time, length or velocity of $\mathrm{A} \beta$ 1-42-infused rats $(P>0.05)$ (Figure $2(\mathrm{~A})$ - (C)). There was slight decrease but not statistically significant in the time spent in the hole and entries into the hole between vehicle-infused and $A \beta$ 1-42infused group $(P>0.05)$. CT extract $(100,200 \mathrm{mg} / \mathrm{kg})$ did not alter the time spent in the hole or entries into the hole of A $\beta$ 1-42-infused rats $(P>0.05)$. However, donepezil at $0.75 \mathrm{mg} / \mathrm{kg}$ increased the time spent in the hole and the entry count into the hole of $A \beta$ 1-42-infused rats $(P<0.05)$ (Figure $2(\mathrm{D})$ and $(\mathrm{E}))$.

\section{Effects of CT or donepezil on inhibitory avoidance task and morris water maze}

In the acquisition trial of the inhibitory avoidance test, there was no difference in the step-through latency between any of the treatment groups (data not shown). However, a significant reduction in the step-through latency in the retention trial was observed in $A \beta$ 1-42-infused groups compared to vehicle-infused group $(P<0.001)$. CT extract $(100,200 \mathrm{mg} \mathrm{kg})$ or donepezil $(0.75 \mathrm{mg} / \mathrm{kg})$ increased the step-through latency of the retention trial in $\mathrm{A} \beta 1$-42-infused rats $(P<0.001)$ (Figure $3(\mathrm{~A})$ ).

The spatial performance over eight trials of four training days (from day 10 to day13 after A $\beta$ 1-42 infusion), particularly trials $3 \sim 7$, in $A \beta$ 1-42-infused group was significantly impaired compared to that of vehicle-infused group $(P<0.01)$. CT extract $(200 \mathrm{mg} / \mathrm{kg})$ or donepezil $(0.75 \mathrm{mg} / \mathrm{kg})$ after $A \beta$ 1-42 infusion ameliorated the impairment of spatial performance caused by A $\beta 1-42$ infusion $(P<0.05$, $P<0.01$ ) (Figure $3(\mathrm{~B})$ ).

Compared to vehicle-infused group, $A \beta$ 1-42-infused group showed a significant decrease in the time spent in the platform-quadrant during training $(P<0.001)$. All doses of CT extract and donepezil $(0.75 \mathrm{mg} / \mathrm{kg})$ significantly increased the time spent in the platform-quadrant relative to $\mathrm{A} \beta$ 1-42-infused group $(P<0.001)$ (Figure 3 $(C))$. In the swimming velocity, there were no differences between vehicle-infused group, A $\beta$ 1-42-infused group, or CT extract or donepezil treatment groups $(P>0.05)$ (Figure $3(\mathrm{D})$ ).

\section{Effects of $C T$ or donepezil on $A \beta$ 1-42 deposition}

The deposition of amyloid $\beta$ protein in the brains of $A \beta$ 1-42-infused rats was more than that of vehicle-infused rats (Figure 4 (A) and (B)). CT extract (100, $200 \mathrm{mg} / \mathrm{kg}$ ) or donepezil $(0.75 \mathrm{mg} / \mathrm{kg})$ decreased the deposition of amyloid $\beta$ protein in the brains of $A \beta$ 1-42-infused rats (Figure $4(C)-(E)$ ). The effects of CT extract or donepezil on the ratio of $A \beta$ 1-42 deposition in the brains of $A \beta$ 1-42-infused rats are shown in Figure $4(\mathrm{~F})$. Compared to vehicle-infused group, $A \beta$ 1-42-infused group showed a significantly greater ratio of $A \beta 1-42$ deposition in the brain $(P<0.01)$. CT extract $(100,200 \mathrm{mg} / \mathrm{kg})$ or donepezil $(0.75 \mathrm{mg} / \mathrm{kg})$ decreased the ratio of $A \beta 1-42$ deposition in the brain of $\mathrm{A} \beta 1$-42-infused rats $(P<0.05, P<0.01)$.

\section{Effects of CT or donepezil on brain neurotransmitters and their metabolites}

A $\beta$ 1-42 continual infusion decreased cortical and hippocampal acetylcholine levels $(P<0.05$ for cortex, $P<0.001$ for hippocampus), but only decreased hippocampal choline levels $(P<0.01)$. CT extract $(200 \mathrm{mg} / \mathrm{kg})$ or donepezil 


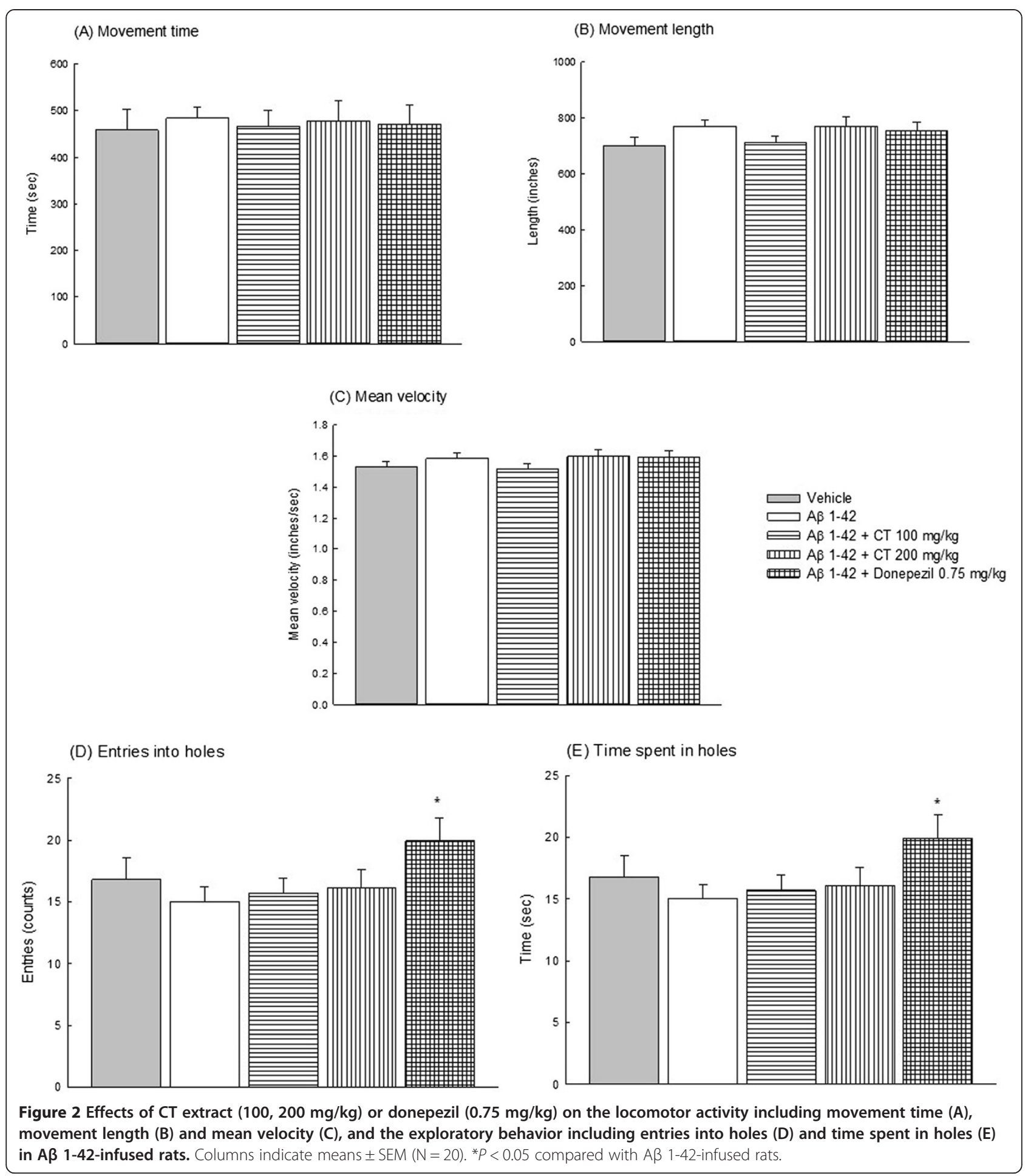

$(0.75 \mathrm{mg} / \mathrm{kg})$ reversed this decrease in cortical and hippocampal acetylcholine levels in A $\beta$ 1-42-infused rats $(P<0.05)$ (Table 1$)$.

Continuous infusion of $A \beta$ 1-42 decreased cortical and hippocampal DA levels $(P<0.01)$, but only decreased hippocampal NE levels $(P<0.05)$. CT extract $(100$ and
$200 \mathrm{mg} / \mathrm{kg}$ ) only reversed the decrease in DA levels in the hippocampus of $\mathrm{A} \beta 1$-42-infused rats $(P<0.05)$. Donepezil did not alter the decrease in hippocampal DA levels $(P>0.05)$, but exaggerated the decrease in hippocampal NE levels in A $\beta 1$-42-infused rats $(P<0.01)$ (Table 1). 


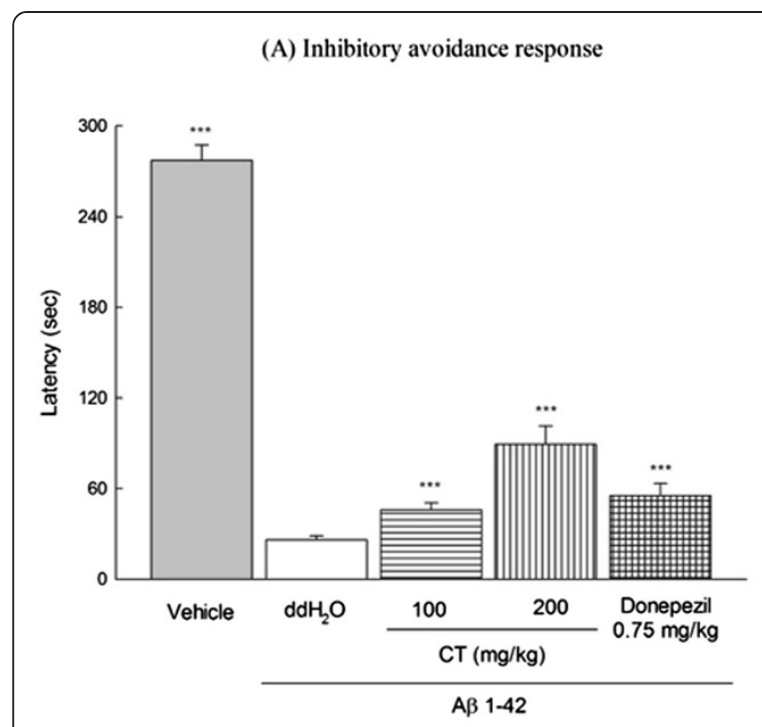

(C) Probe test of Morris water maze

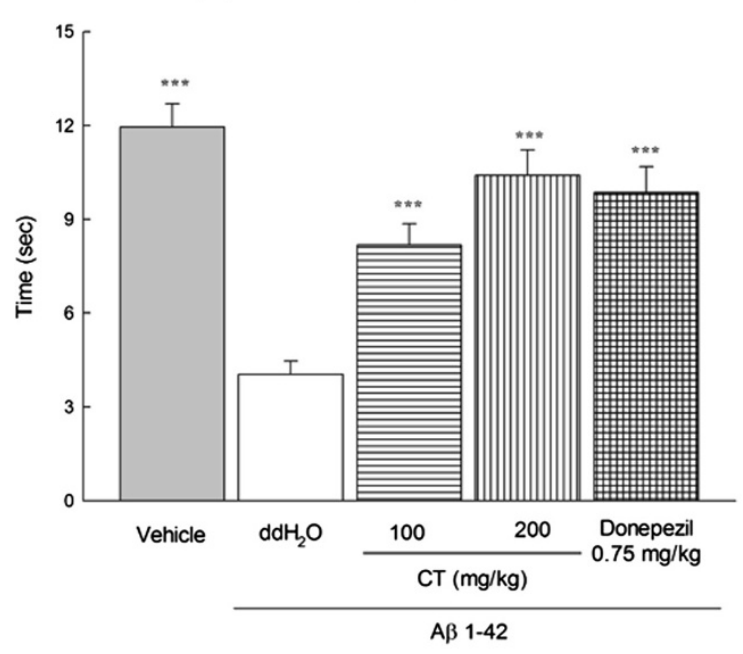

(B) Spatial performance of Morris water maze

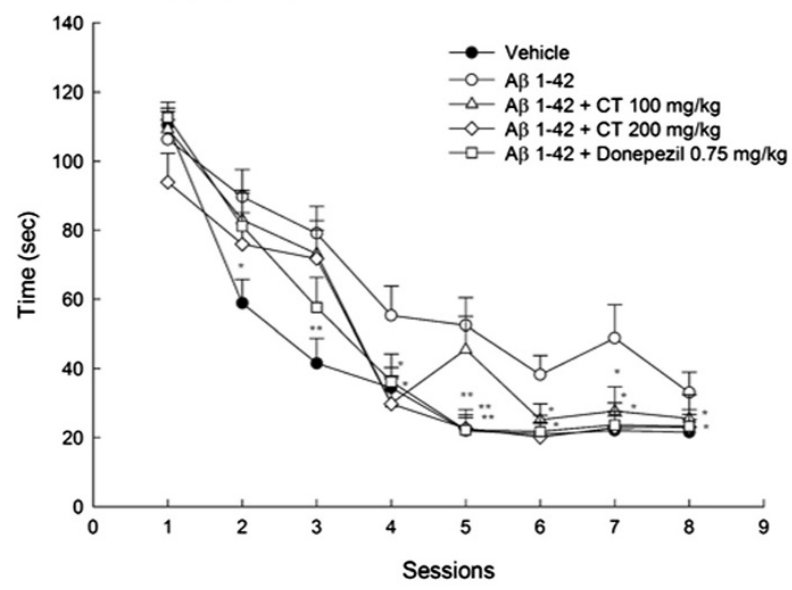

(D) Swimming speed

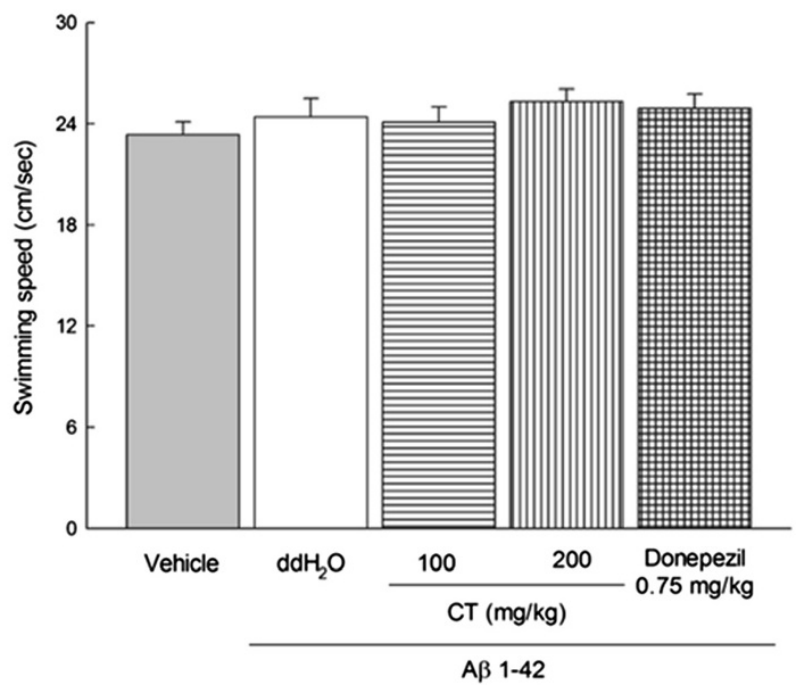

Figure 3 Effects of CT extract $(100,200 \mathrm{mg} / \mathrm{kg})$ or donepezil $(0.75 \mathrm{mg} / \mathrm{kg})$ on the step-through latency of the inhibitory avoidance task $(A)$, the spatial performance (B), probe test (C), and swimming velocity (D) of the Morris water maze in A $\beta$ 1-42-infused rats. Columns indicate means $\pm \operatorname{SEM}(\mathrm{N}=20) .{ }^{*} P<0.05,{ }^{*} P<0.01,{ }^{* * *} P<0.001$ compared with $\mathrm{A} \beta 1$-42-infused rats.

\section{Effects of CT or donepezil on Brain AChE, MAO-A and MAO-B activity}

Continuous infusion of $A \beta$ 1-42 increased cortical and hippocampal AChE activities $(P<0.05$ for hippocampus, $P<0.01$ for cortex). CT extract $(200 \mathrm{mg} / \mathrm{kg}$ ) or donepezil $(0.75 \mathrm{mg} / \mathrm{kg})$ only reversed the increase in cortical AChE activity in $\mathrm{A} \beta 1$-42-infused rats $(P<0.05$ for donepezil, $P<0.01$ for $\mathrm{CT}$ ) (Figure $5(\mathrm{~A})$ and $(\mathrm{B})$ ).

Continuous infusion of $A \beta$ 1-42 increased cortical MAO-A and MAO-B activity (Figure $5(\mathrm{C})$ and $(\mathrm{E}), P<0.05, P<0.01$ ), but decreased hippocampal MAO-A and MAO-B activities in the rats (Figure $5(\mathrm{D})$ and $(\mathrm{F}), P<0.05)$. CT extract at $200 \mathrm{mg} / \mathrm{kg}$ only reversed the increase in the cortical MAO-A activity in A $\beta$ 1-42-infused rats (Figure 5 (C),
$P<0.01)$. Donepezil $(0.75 \mathrm{mg} / \mathrm{kg})$ did not change the alteration of MAO-A and MAO-B activities in $A \beta 1$ 42 -infused rats (Figure $5(\mathrm{C})-(\mathrm{F}), P>0.05)$.

\section{Discussion}

Many reports from cell culture assays and animal experiments evidenced that $A \beta$ is the key protein in $A D$ patients $[2,3]$. A $\beta$ 1-42 induced neuronal damage and apoptosis via oxidative stress in vitro [2,3]. Intracisternal injection of $A \beta$ 1-42 into rats produced memory impairment, changes in brain morphology, and cholinergic neuronal degeneration $[3,4]$. In this study, the continual infusion of $A \beta \quad 1-42$ to the cerebral ventricle by an osmotic pump (Alzet 2002) caused behavioral deficits including exploratory behavior, 


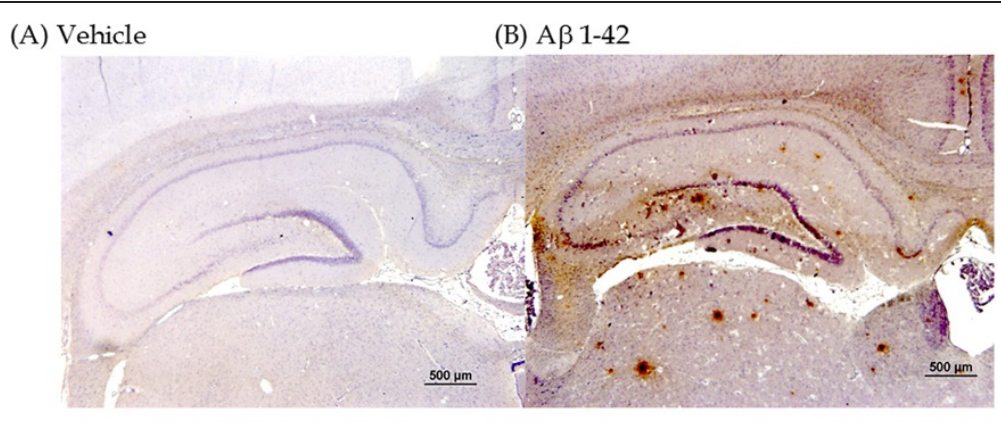

(C) CT $100 \mathrm{mg} / \mathrm{kg}$

(D) CT $200 \mathrm{mg} / \mathrm{kg}$

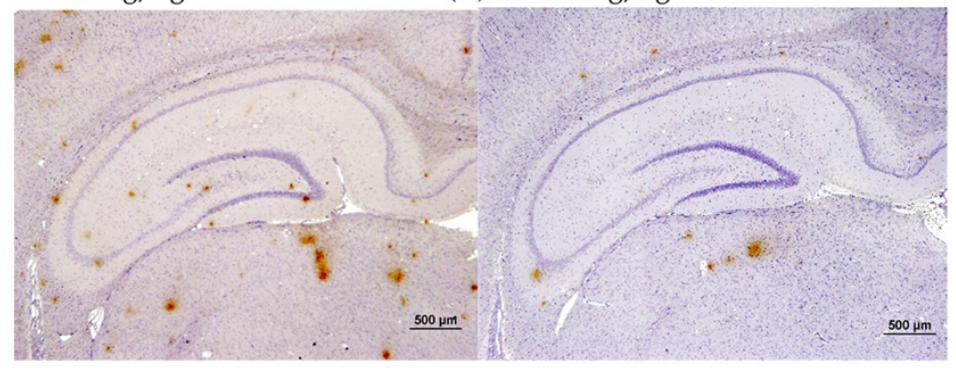

(E) Donepezil $0.75 \mathrm{mg} / \mathrm{kg}$

(F) The ratio of amyloid deposition
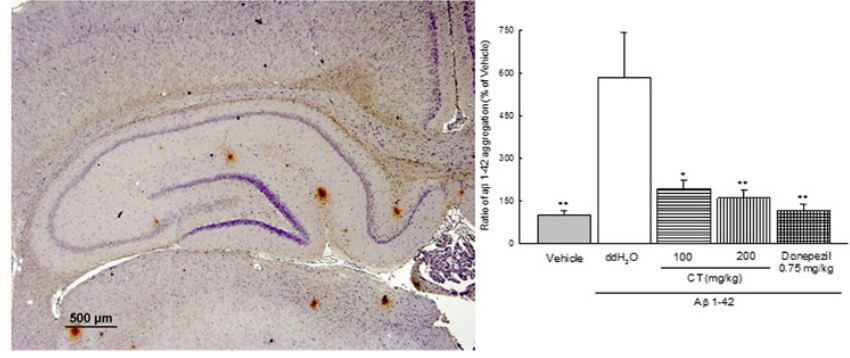

Figure 4 Effects of $C T$ extract $(100,200 \mathrm{mg} / \mathrm{kg})$ or donepezil $(0.75 \mathrm{mg} / \mathrm{kg})$ on the $A \beta$ 1-42 deposition in $A \beta$ 1-42-infused rats. (A) Vehicle-infused group, (B) Aß 1-42-infused group, (C) $\subset$ extract (100 mg/kg)-treated group, (D) $\subset$ extract (200 mg/kg)-treated group, (E) donepezil (0.75 mg/kg)-treated group, (F) the ratio of amyloid depsotion. Columns indicate means \pm SEM $(\mathrm{N}=6) .{ }^{*} P<0.05$, ${ }^{* *} P<0.01$ compared with A $\beta$ 1-42-infused rats.

inhibitory avoidance response, and spatial performance of Morris water maze in rats. These symptoms were similar to previous reports $[3,4]$. Donepezil, a selective AChE inhibitor, possess neuroprotective activity against A $\beta$ induced toxicity in vitro and in vivo $[19,20]$. Our present data are consistent with the above report [20] showing that donepezil ameliorated the behavior deficits caused by $A \beta 1-42$ infusion in rats. The intra-gastric administration of CT extract $(100,200 \mathrm{mg} / \mathrm{kg}$ ) throughout $A \beta$ 1-42 infusion period ameliorated the observed behavior deficits caused by $A \beta 1-42$. This memory-improving effect is consistent with other reports showing that total phenylethanoid glycosides of Cistanche species could protect the impairment of inhibitory avoidance response caused by an acute intracisternal injection of $A \beta$ 25-35 in mice [6]. Recent clinical report also indicated that AD patients given with CT glycosides for 48 weeks showed no exacerbation of cognitive function [21]. Moreover, CT extract at used dosage $(100,200 \mathrm{mg} / \mathrm{kg})$ contained echinacoside (25.4, $50.8 \mathrm{mg})$, acteoside (3.8, $7.6 \mathrm{mg}$ ) and isoacteoside (4.1,
$8.2 \mathrm{mg}$ ) according to quantity assay performed in this study. Echinacoside $(50 \mathrm{mg} / \mathrm{kg})$ and acteoside $(1 \mathrm{mg} / \mathrm{kg})$ can prevent the memory impairments caused by scopolamine in mice $[11,12]$. Thus, we suggest that $\mathrm{CT}$ is a potential anti-amnesic and anti-dementia plant when it is quantified and standardized through its phenylethanoid glycosides, particularly echinacoside, acteoside and isoacteoside.

According to amyloid cascade hypothesis, memory deficits caused by $A \beta$ are due to intracellular oxidative stress and neuronal apoptosis promoted by $A \beta$ formation and subsequent aggregation and deposition $[2,3]$. $A \beta$ deposition is closely associated with the dysfunction of central cholinergic neuronal circuits in the basal forebrain $[2,3]$. The dysfunction of central cholinergic neuronal systems, including decreased brain acetylcholine levels and an upregulation of $\mathrm{AChE}$ activity, has been shown to be related to the degrees of amnesia and $\mathrm{A} \beta$ deposition in $\mathrm{AD}$ brain $[2,3]$. According to our above results, we further investigated the effects of $\mathrm{CT}$ extract or donepezil on $\mathrm{A} \beta$ - 
Table 1 Effects of CT extract (100, $200 \mathrm{mg} / \mathrm{kg})$ or donepezil $(0.75 \mathrm{mg} / \mathrm{kg})$ on the levels of cortical and hippocampal neurotransmitters and their metabolites in $A \beta$ 1-42-infused rats

\begin{tabular}{|c|c|c|c|c|c|c|c|}
\hline & \multicolumn{7}{|c|}{ The levels in cortex ( $\mathrm{nmol} / \mathrm{mg}$ protein for $\mathrm{ACh}$ and choline, $\mathrm{ng} / \mathrm{g}$ protein for other transmitters) } \\
\hline & $\mathrm{ACh}$ & Choline & MHPG & NE & DOPAC & HVA & DA \\
\hline Vehicle & $224.25 \pm 25.55^{* *}$ & $629.00 \pm 98.35$ & $26.35 \pm 2.72$ & $15.68 \pm 0.76$ & $16.75 \pm 1.70^{*}$ & $3.71 \pm 0.58$ & $3.92 \pm 0.44^{* *}$ \\
\hline$A \beta 1-42$ & $141.35 \pm 7.95$ & $553.10 \pm 31.55$ & $23.27 \pm 1.97$ & $13.86 \pm 1.29$ & $11.66 \pm 1.13$ & $2.76 \pm 0.43$ & $2.33 \pm 0.28$ \\
\hline \multicolumn{8}{|l|}{$\mathrm{CT}$ extract } \\
\hline $100 \mathrm{mg} / \mathrm{kg}$ & $145.98 \pm 18.78$ & $716.40 \pm 69.81$ & $29.91 \pm 4.91$ & $15.94 \pm 1.30$ & $13.89 \pm 3.03$ & $4.29 \pm 0.93$ & $2.95 \pm 0.65$ \\
\hline $200 \mathrm{mg} / \mathrm{kg}$ & $181.49 \pm 13.71^{*}$ & $693.45 \pm 48.05$ & $24.51 \pm 4.16$ & $10.31 \pm 1.07$ & $9.50 \pm 2.10$ & $2.98 \pm 0.85$ & $2.23 \pm 0.33$ \\
\hline \multirow[t]{3}{*}{ Donepezil } & $168.32 \pm 6.58^{*}$ & $467.26 \pm 32.85$ & $15.16 \pm 2.51^{*}$ & $10.73 \pm 2.33$ & $10.49 \pm 2.38$ & $2.42 \pm 0.78$ & $3.10 \pm 0.46$ \\
\hline & \multicolumn{7}{|c|}{ The levels in hippocampus (nmol/mg protein for ACh and choline, ng/g protein for other transmitters) } \\
\hline & ACh & Choline & MHPG & NE & DOPAC & HVA & DA \\
\hline Vehicle & $72.88 \pm 8.64^{* * *}$ & $295.26 \pm 18.06^{* *}$ & $639.83 \pm 53.38$ & $63.64 \pm 2.56^{*}$ & $5.87 \pm 0.92$ & $3.68 \pm 0.41$ & $5.36 \pm 0.75^{* * *}$ \\
\hline$A \beta 1-42$ & $28.45 \pm 2.62$ & $173.10 \pm 18.15$ & $639.23 \pm 68.26$ & $52.67 \pm 4.21$ & $5.13 \pm 0.80$ & $3.39 \pm 0.36$ & $1.00 \pm 0.21$ \\
\hline \multicolumn{8}{|l|}{$\mathrm{CT}$ extract } \\
\hline $100 \mathrm{mg} / \mathrm{kg}$ & $43.48 \pm 3.14$ & $238.20 \pm 23.91$ & $785.42 \pm 139.84$ & $57.98 \pm 10.69$ & $4.98 \pm 0.78$ & $3.90 \pm 0.61$ & $2.40 \pm 0.65^{*}$ \\
\hline $200 \mathrm{mg} / \mathrm{kg}$ & $50.44 \pm 8.98^{*}$ & $234.69 \pm 13.26$ & $704.84 \pm 59.68$ & $63.21 \pm 4.79$ & $5.98 \pm 1.90$ & $3.78 \pm 0.64$ & $3.09 \pm 1.27^{*}$ \\
\hline Donepezil & $51.11 \pm 9.54^{*}$ & $177.69 \pm 46.80$ & $455.27 \pm 46.81^{*}$ & $32.80 \pm 3.88^{* * *}$ & $3.19 \pm 1.00$ & $2.45 \pm 0.33$ & $1.33 \pm 0.37$ \\
\hline
\end{tabular}

Columns indicate means \pm SEM $(N=6) .{ }^{*} P<0.05,{ }^{* *} P<0.01,{ }^{* * *} P<0.001$ compared with $A \beta 1$-42-infused rats.

induced pathological changes in rats. We found that $A \beta 1-42$ continual infusion caused a major pathological change in $A \beta$ deposition around hippocampus and prefrontal cortex and in a significant associated biochemical alteration: a decrease in acetylcholine and choline levels and an up-regulation of AChE activity particularly in hippocampal areas. These pathological symptoms were similar to other reports $[4,22]$ showing that intracisternal injection of $A \beta$ 1-42 over 2 weeks causes $A \beta$ deposition in rat brain using immunohistochemical stain, and then causes an up-regulation in AChE activity within and around senile plaques. This up-regulation encourages the assembly of $A \beta$ into fibrils, and these $A \beta$ fibrils ultimately lead to $A \beta$ neurotoxicity and particularly cholinergic dysfunction [23]. In $A \beta$ 1-42-infused rats, donepezil decreased the ratio of $A \beta$ deposition and the alteration in cortical AChE activity, and restored ACh levels in all brain areas. Our present data were consistent with another report $[19,20]$ showing that donepezil might inhibit AChE activation to produce neuroprotective and memory-improving effects against $A \beta$ 1-42. CT extract $(100,200 \mathrm{mg} / \mathrm{kg}$ ) also decreased the deposition of $\mathrm{A} \beta$, especially in hippocampal areas, but only $200 \mathrm{mg} / \mathrm{kg}$ dosage reversed the alterations in cortical AChE activity and the decrease in cortical and hippocampal acetylcholine levels. From these pathological and biochemical results, we suggested that CT extract at $200 \mathrm{mg} / \mathrm{kg}$ reversed cortical and hippocampal cholinergic function by decreasing the deposition of $\mathrm{A} \beta$. Other reports indicated that total phenylethanoid glycosides of Cistanche species or acteoside could protect the memory deficits or neuronal damage caused by $A \beta$ 25-35 through an antioxidant mechanism and decreasing the ratio of $\mathrm{Bax} / \mathrm{Bcl} 2$ in vivo or in vitro [6,24]. Recent report further indicated that acteoside inhibited $A \beta \quad$ 1-42 aggregation in a dose-dependent manner by using the thioflavin-T assay [25]. Echinacoside decreased AChE activity in SAMP/8 mice [12]. Thus, we suggest that the memory-improving effects of $\mathrm{CT}$ extract might be related to decrease $A \beta$ deposition and neurotoxicity, which leads to a reversal of negative changes in cortical and hippocampal cholinergic function.

Clinical researchers found that AD patients have complex neurochemical disturbances including the catecholaminergic, cholinergic and glutaminergic neuronal systems [26]. Some reports also found that AD patients have increased MAO-B activity compared to healthy controls, and this increased MAO-B activity might reflect abnormalities in the dopaminergic systems [27]. In AD-like rat model, $A \beta \quad 1-42$ also causes catecholaminergic dysfunction [14]. Some nootropics or selegiline improved $A \beta$-induced memory deficits via enhancing catecholaminergic activity or modulating MAO activities [4,28]. In this study, $A \beta$ 1-42 continual infusion also caused a decrease in cortical and hippocampal DA levels and in hippocampal NE levels. We also found that $A \beta$ 1-42 continual infusion led to a differential alteration of cortical and hippocampal MAO activities, which included an up-regulation in cortical MAO-A and MAO-B activities and a downregulation in hippocampal MAO-A and MAO-B activities. These pathological symptoms of catecholaminergic dysfunction were similar to other reports $[14,27]$. Donepezil did not alter these catecholaminergic change caused by $A \beta$ 1-42 infusion, but decreased hippocampal NE and MHPG levels compared to $A \beta$ 1-42-infused rats This data is 

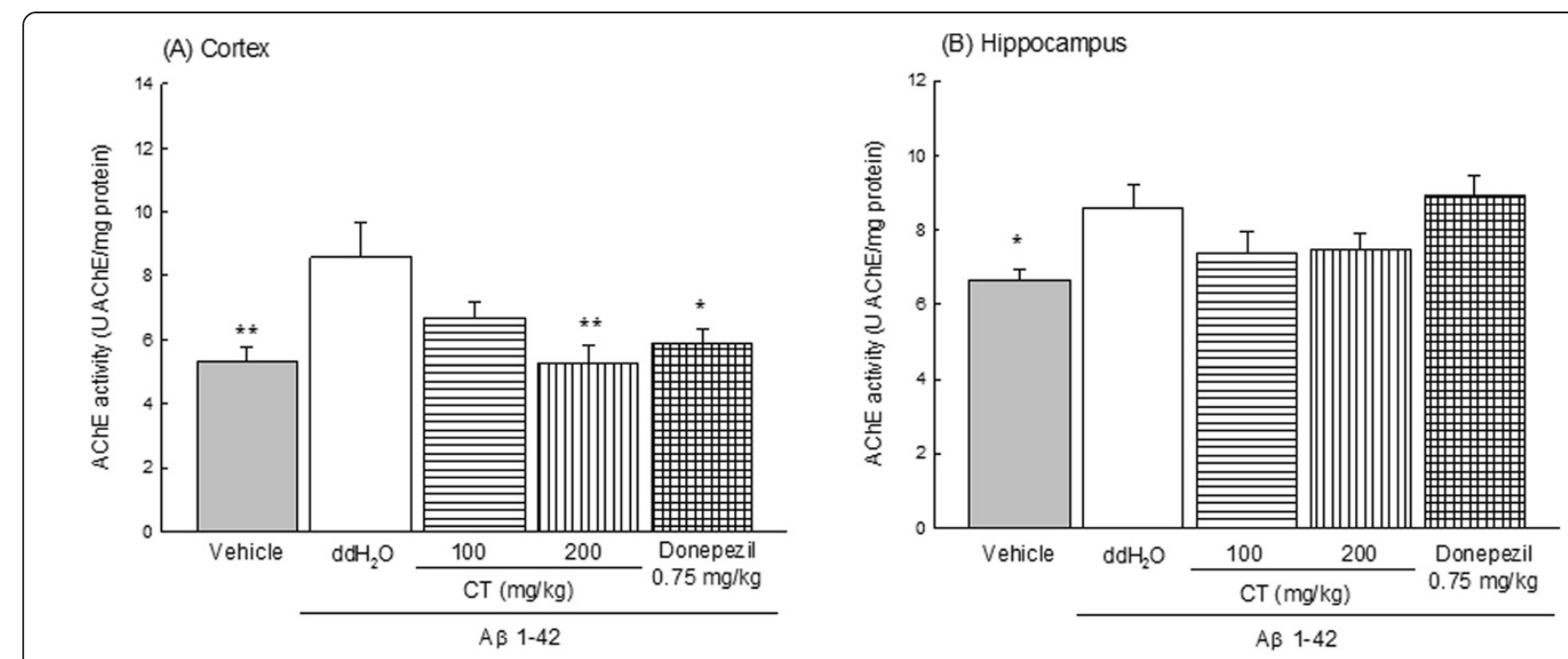

(C) Cortex

(D) Hippocampus
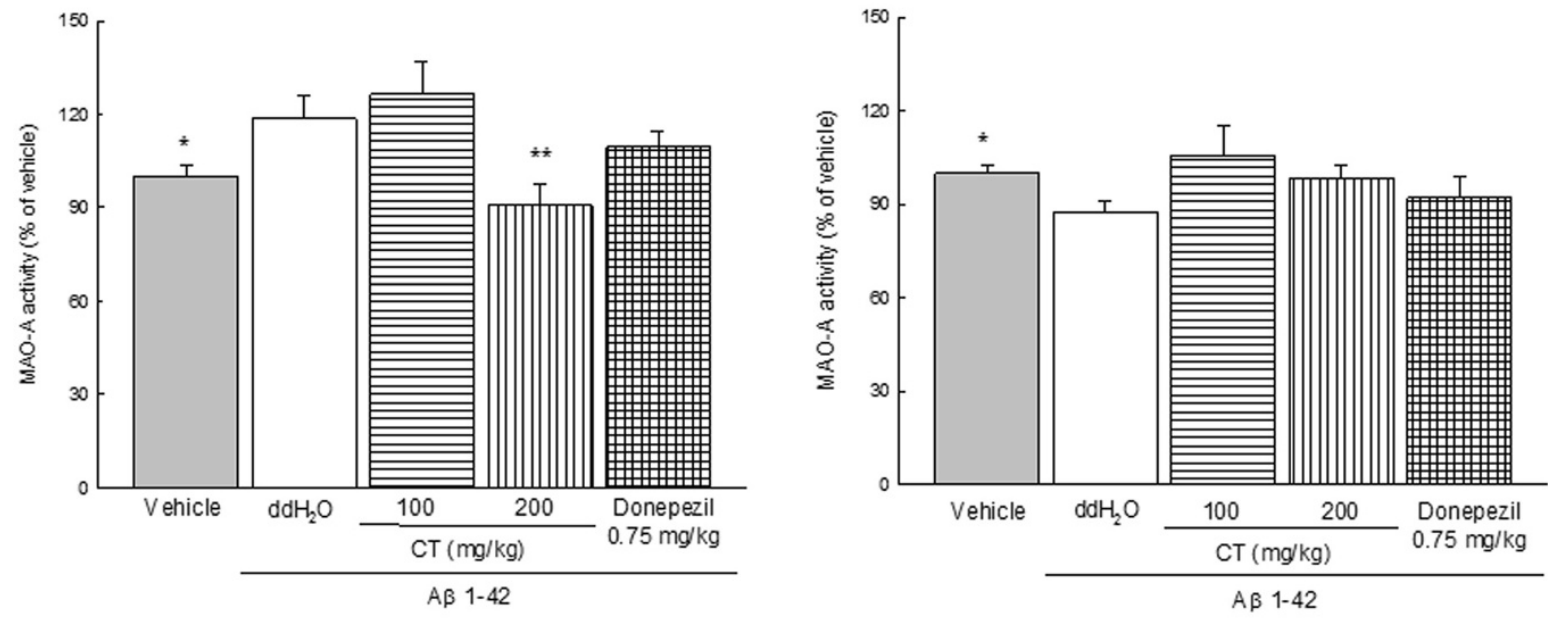

(E) Cortex
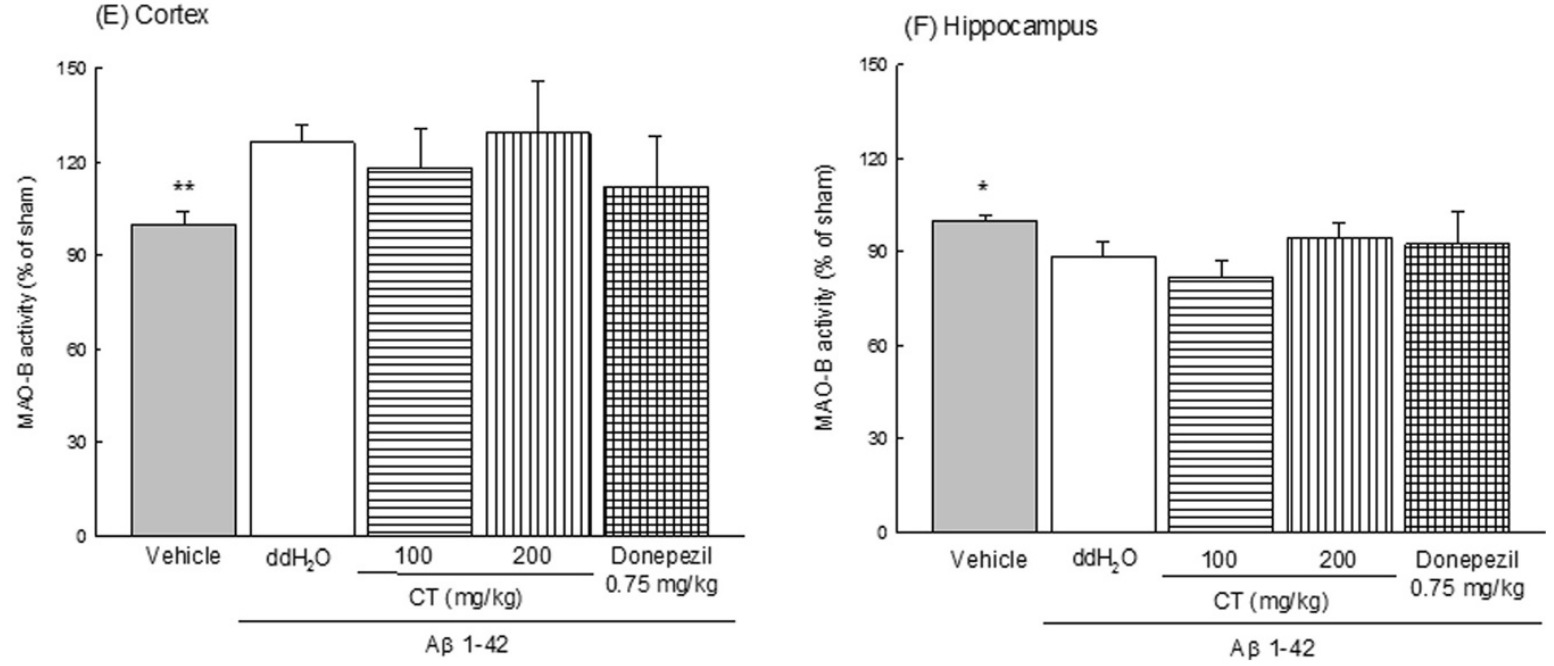

Figure 5 Effects of CT extract $(100,200 \mathrm{mg} / \mathrm{kg})$ or donepezil $(0.75 \mathrm{mg} / \mathrm{kg})$ on the AChE (A and B), MAO-A (C and D) and MAO-B (E and F) activity in the cortex (A, $C$ and $E)$ and hippocampus $(B, D$ and $F)$ of $A \beta$ 1-42-infused rats. Columns indicate means $\pm S E M(N=6)$. ${ }^{*} P<0.05,{ }^{*} P<0.01$ compared with $A \beta 1$ 1-42-infused rats. 
consistent with another report $[19,20]$ showing that donepezil possesses memory-improving effects against $A \beta$ 1-42 that act mainly through its selective AChE inhibiting effects but it possibly causes region-specific changes in some neurotransmitters. CT extract only reversed the decrease in hippocampal DA levels and the up-regulation of cortical MAO-A activity caused by A $\beta$ 1-42 infusion. Hence, we suggest that CT extract at $200 \mathrm{mg} / \mathrm{kg}$ reversed the negative effects on hippocampal dopaminergic function mainly by decreasing the deposition of $A \beta$ in the hippocampal areas. However, donepezil also decreased the deposition of $A \beta$, but did not affect the hippocampal dopaminergic function.

\section{Conclusion}

CT is a potential anti-amnesic and anti-dementia plant based on our present data and other reports [6-8,21]. The contents of echinacoside and acteoside in this used dosage of CT extract is sufficient to produce memoryimproving effects in SAMP/8 mice or scopolamineinduced amnesia [11,12]. Hence, we further suggest that, as an anti-dementia plant, it is important to standardize the content range of echinacoside, acteoside and isoacteoside in $\mathrm{CT}$ extract. Furthermore, the memory-improving mechanism of CT extract, which is different from that of donepezil that it decreased $A \beta$ deposition and cholinergic dysfunction by inhibiting $\mathrm{AChE}$ activation and activating nicotinic receptors and phosphoinositide 3-kinase/Akt pathways $[19,20]$, is due to the decrease in $A \beta$ deposition and reversal of the cholinergic and hippocampal dopaminergic dysfunction. Moreover, other reports have indicated that total phenylethanoid glycosides of the Cistanche species possess neuroprotective and memory-enhancing effects through their antioxidant and neurotrophic activities $[9,29,30]$. Echinacoside and acteoside also possess neuroprotective effects in $\mathrm{H}_{2} \mathrm{O}_{2}$ - MPTP- or $\mathrm{A} \beta$ 25-35-induced neurotoxicity via antioxidant and neurotrophic activities $[24,31,32]$. Hence, whether the protective effect of CT extract in AD-like rat model acts through anti-aggregating, neuroprotective or neurotrophic effects against $A \beta$ should be investigated in the future.

\section{Abbreviations \\ A 3 1-42: Amyloid $\beta$ peptide 1-42; AChE: Acetylcholinesterase; AD: Alzheimer's disease; CT: Cistanche tubulosa (Schenk) R. Wight; MAO: Monoamine oxidase.}

\section{Competing interests}

The authors declare that they have no competing interests.

\section{Authors' contributions}

CRW and MHS carried out all the experimentation, acquisition of data conceived, designed, supervised the study, drafted and revised the manuscript. HCL identified the plants, and provided the plant extracts. All authors read and approved the final manuscript.

\section{Acknowledgements}

We thank the financial support of National Sciences Council NSC101-2320-B039-050, NSC101-2120-M-009-008 and NSC102-2320-B-039-037. We also thank that $C T$ extract was given by Sinphar Pharmaceutical Co. Ltd.

\section{Author details}

Department of Chinese Pharmaceutical Sciences and Chinese Medicine Resources, College of Pharmacy, China Medical University, No. 91, Hsieh Shih Road, Taichung 40402, Taiwan. ${ }^{2}$ School of Pharmacy, National Defense Medical Center, No. 161, Sec. 6, Minquan E. Rd., Neihu Dist., Taipei 11490, Taiwan. ${ }^{3}$ Sinphar Pharmaceutical Co., Ltd., Sinphar Group (Taiwan), Research \& Development Center, No. 84, Chung Shan Rd., Chung Shan Village,

Tung-Shan Shine, I-Lan 26944, Taiwan.

Received: 22 October 2013 Accepted: 29 May 2014

Published: 26 June 2014

\section{References}

1. Nizzari M, Thellung S, Corsaro A, Villa V, Pagano A, Porcile C, Russo C, Florio T: Neurodegeneration in Alzheimer disease: role of amyloid precursor protein and presenilin 1 intracellular signaling. J Toxicol 2012, 2012:187297.

2. Parihar MS, Hemnani T: Alzheimer's disease pathogenesis and therapeutic interventions. J Clin Neurosci 2004, 11:456-467.

3. Tran MH, Yamada K, Nabeshima T: Amyloid beta-peptide induces cholinergic dysfunction and cognitive deficits: a minireview. Peptides 2002, 23:1271-1283

4. Yamada K, Tanaka T, Mamiya T, Shiotani T, Kameyama T, Nabeshima T: Improvement by nefiracetam of beta-amyloid-(1-42)-induced learning and memory impairments in rats. Br J Pharmacol 1999, 126:235-244.

5. Shao ML, Ma XW, Wu Z, Yu WM, Chen XN: Chinese Pharmacopoeia. In 2005th edition. Edited by Chinese PC. Bejing: Chemical and Industrial Publisher; 2005:90

6. Liu FX, Wang XW, Luo L, Xin HNB, Wang XF: The effects of glycosides of cistanche on learning and memory in $\beta$-amyloid peptide induced Alzheimers disease in mice and its possible mechanism. Chin Pharmacol Bull 2006, 22:599-601.

7. Luo L, Wang XW, Yang M, Yang S, Yang YX: Effects of glycosides of cistanche on learning and memory function in rat undertaken bilateral common carotid artery ligation and its possible mechanism. Chin J New Drugs Clin Remed 2007, 26:401-405.

8. Luo L, Wang XW, Liu FX, Yang S, Wang T: Protective effects of glycosides of cistanche on behaviors and memory impairment mice induced by aluminum trichloride. Chin J New Drugs Clin Remed 2007, 26:33-36.

9. Bao B, Tang XY, Tian H, Tong $Y$, Wu WH, Hong YK: Antioxidant activity of extracts from desert living Cistanche tubulosa (Schrenk) R. Wright Shanghai J Tradit Chin Med 2010, 44:68-71.

10. Jiang Y, Li SP, Wang YT, Chen XJ, Tu PF: Differentiation of Herba Cistanches by fingerprint with high-performance liquid chromatography-diode array detection-mass spectrometry. J Chromatogr A 2009, 1216:2156-2162.

11. Lee KY, Jeong EJ, Lee HS, Kim YC: Acteoside of Callicarpa dichotoma attenuates scopolamine-induced memory impairments. Biol Pharm Bull 2006, 29:71-74.

12. He W, Fang T, Tu P: Research progress on pharmacological activities of echinacoside. China J Chin Mater Med 2009, 34:476-479.

13. Myhrer T: Neurotransmitter systems involved in learning and memory in the rat: a meta-analysis based on studies of four behavioral tasks. Brain Res Rev 2003, 41:268-287.

14. Itoh A, Nitta A, Nadai M, Nishimura K, Hirose M, Hasegawa T, Nabeshima T: Dysfunction of cholinergic and dopaminergic neuronal systems in beta-amyloid protein-infused rats. J Neurochem 1996, 66:1113-1117.

15. Wu CR, Lin LW, Hsieh CL, Wang WH, Lin YT, Hsieh MT: Petroleum ether extract of Cnidium monnieri ameliorated scopolamine-induced amnesia through adrenal gland-mediated mechanism in male rats. $J$ Ethnopharmaco 2008, 117:403-407.

16. Glowinski J, Iversen LL: Regional studies of catecholamines in the rat brain, I: the disposition of [3H]norepinephrine, [3H]dopamine and $[3 \mathrm{H}]$ dopa in various regions of the brain. J Neurochem 1966, 13:655-669.

17. Ellman GL, Courtney KD, Andres V Jr, Feather-Stone RM: A new and rapid colorimetric determination of acetylcholinesterase activity. Biochem Pharmacol 1961, 7:88-95.

18. Zhou M, Panchuk-Voloshina N: A one-step fluorometric method for the continuous measurement of monoamine oxidase activity. Anal Biochem 1997, 253:169-174.

19. Noh MY, Koh SH, Kim Y, Kim HY, Cho GW, Kim SH: Neuroprotective effects of donepezil through inhibition of GSK-3 activity in amyloid-beta-induced neuronal cell death. J Neurochem 2009, 108:1116-1125. 
20. Meunier J, leni J, Maurice T: The anti-amnesic and neuroprotective effects of donepezil against amyloid beta 25-35 peptide-induced toxicity in mice involve an interaction with the sigma1 receptor. Br J Pharmacol 2006, 149:998-1012.

21. Guo Q, Zhou Y, Wang CJ, Huang YM, Lee YT, Su MH, Lu J: An open-label, nonplacebo-controlled study on Cistanche tubulosa glycoside capsules (Memoregain((R))) for treating moderate Alzheimer's Disease. Am J Alzheimers Dis Other Demen 2013, 28:363-370.

22. Nabeshima T, Nitta A: Memory impairment and neuronal dysfunction induced by beta-amyloid protein in rats. Tohoku J Exp Med 1994, 174:241-249.

23. Jazi R, Lalonde R, Qian S, Strazielle C: Regional brain evaluation of acetylcholinesterase activity in PS1/A246E transgenic mice. Neurosci Res 2009, 63:106-114.

24. Wang H, Xu Y, Yan J, Zhao X, Sun X, Zhang Y, Guo J, Zhu C: Acteoside protects human neuroblastoma SH-SY5Y cells against beta-amyloidinduced cell injury. Brain Res 2009, 1283:139-147.

25. Kurisu M, Miyamae Y, Murakami K, Han J, Isoda H, Irie K, Shigemori H: Inhibition of amyloid beta aggregation by acteoside, a phenylethanoid glycoside. Biosci Biotechnol Biochem 2013, 77:1329-1332.

26. Arai H, Ichimiya Y, Kosaka K, Moroji T, lizuka R: Neurotransmitter changes in early- and late-onset Alzheimer-type dementia. Prog Neuropsychopharmacol Biol Psychiatry 1992, 16:883-890.

27. Gulyas B, Pavlova E, Kasa P, Gulya K, Bakota L, Varszegi S, Keller E, Horvath MC Nag S, Hermecz I, Magyar K, Halldin C: Activated MAO-B in the brain of Alzheimer patients, demonstrated by [11C]-L-deprenyl using whole hemisphere autoradiography. Neurochem Int 2011, 58:60-68.

28. Tsunekawa H, Noda Y, Mouri A, Yoneda F, Nabeshima T: Synergistic effects of selegiline and donepezil on cognitive impairment induced by amyloid beta (25-35). Behav Brain Res 2008, 190:224-232.

29. Qi XL, Gu R, Hao XY, Shan KR, Ren XL, Guan ZZ: Protective effects of Herb Cistanches against the neurotoxicity of amyloid peptide in SH-SY5Y cells. J Chin Hosp Pharm 2008, 28:440-442.

30. Choi JG, Moon M, Jeong HU, Kim MC, Kim SY, Oh MS: Cistanches Herba enhances learning and memory by inducing nerve growth factor. Behav Brain Res 2011, 216:652-658.

31. Zhao Q, Gao J, Li W, Cai D: Neurotrophic and neurorescue effects of echinacoside in the subacute MPTP mouse model of Parkinson's disease. Brain Res 2010, 1346:224-236.

32. Kuang $R$, Sun $Y$, Yuan $W$, Lei L, Zheng X: Protective effects of echinacoside, one of the phenylethanoid glycosides, on $\mathrm{H}(2) \mathrm{O}(2)$-induced cytotoxicity in PC12 cells. Planta Med 2009, 75:1499-1504.

doi:10.1186/1472-6882-14-202

Cite this article as: Wu et al.: Reversal by aqueous extracts of Cistanche tubulosa from behavioral deficits in Alzheimer's disease-like rat model: relevance for amyloid deposition and central neurotransmitter function. BMC Complementary and Alternative Medicine 2014 14:202.

\section{Submit your next manuscript to BioMed Central and take full advantage of:}

- Convenient online submission

- Thorough peer review

- No space constraints or color figure charges

- Immediate publication on acceptance

- Inclusion in PubMed, CAS, Scopus and Google Scholar

- Research which is freely available for redistribution 